\title{
My Second Life: A Survey Of Chinese Immigrants In New Zealand
}

\author{
Deniss T C Yeung, Waikato Institute of Technology, New Zealand
}

\begin{abstract}
The purpose of this study was to identify the reasons for Chinese immigrants coming to New Zealand; the things that they enjoyed and disliked while they lived here and their future intentions. A face-to-face in-depth interview method with open-ended questions was used. A snow-ball sample of sixty was recruited. The main reason for Chinese immigrant respondent's first coming to New Zealand was to study; the main reason for deciding to stay was because of the natural environment and friendly people. Minor racism was experienced by many respondents, and young Chinese professionals were planning to go back to China or move to other Western countries for better career opportunities or higher quality tertiary education. The findings are useful for potential Chinese immigrants' decision making, also for government, social service agencies, and strategic planning for education institutes.
\end{abstract}

Keywords: New Zealand; Chinese Immigrants; Like; Dislike

\section{INTRODUCTION}

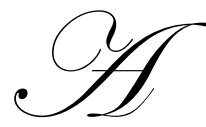

ccording to Anderson (1997, p. 11) people migrate to other countries because of one reason, 'hope'. Hope that things will be better economically, with better working conditions and living standards as well as family reunion.

In the 1860s early Chinese male immigrants came to New Zealand from Guangdong, China predominantly as gold miners in Otago, then migrated on to the West Coast. Few struck it rich, and most remained in enforced bachelorhood, poverty-stricken and stranded in a strange land (Ip, 2006, p. 106).

Chinese immigrants in the $21^{\text {st }}$ century have different reasons for coming to New Zealand and they are generally well-educated professionals or business people with transferable skills. Many have chosen to come because they want to raise their children in a less competitive educational environment, or because they want a more leisurely lifestyle (Ip, 2006, p. 109).

Reijgersberg (2009) in her community profile confirms that the main reason for Chinese to migrate to New Zealand is for a better life in a new country with a different culture. Other reasons she identifies are education, reunification with family and business.

Given New Zealand is an English speaking western country, Chinese migrants can expect to face a wide range of difficulties because of cultural, social and economic differences.

Similarly, research by the University of Waikato in New Zealand found that language problems, failure to find employment, separation from family and community, negative public attitudes and traumatic experiences prior to migration are key factors associated with increased risk of mental disorders among Asian immigrants, refugees and student sojourners (Ho, Au, Bedford, \& Cooper, 2003, p. 49).

A later New Zealand study highlighted language difficulties and feelings of being a burden to family as being significant difficulties faced by older Asian people, as well as lacking knowledge about services like Accident Compensation Commission (University of Waikato, 2007, p. 18). 
When immigrants find that their new home does not meet expectations, some of them might choose to go back to their original country or to move to another new country. There is very little that government policy can do to stop people leaving. Permanent residence granted to business migrants might merely provide a stepping stone to Australia as evidenced by the fact that New Zealand did not have permanent immigration gain in the late 1980s/early 1990s (New Zealand Planning Council, 1991, p 58).

A report by the Organisation for Economic Cooperation and Development (OECD) shows that 24.2 per cent of all New Zealand-born people with tertiary educations now live overseas. The report also shows that immigrants are more highly educated than the average New Zealander, reflecting a selection system that targets skilled migrants (Collins, 2005, para. $2 \& 14$ ).

Immigration statistics for May 2011 recorded permanent and long-term departures to Australia outnumbering arrivals by 3300 (“Grass looks greener," 2011, para. 3). Therefore it is essential to study whether $21^{\text {st }}$ century Chinese immigrants are really fulfilling their hopes in New Zealand and settling well; or facing too many difficulties, feeling disappointed, then deciding to leave for another country or go back to China. In either case, knowing the reasons will help potential Chinese immigrants to make wiser decisions as well as helping New Zealand provide relevant assistance and services for Chinese immigrants so as to keep them in New Zealand as productive citizens. Otherwise the brain drain problem will apply not just to New Zealand Kiwis but also Chinese Kiwis.

\section{BACKGROUND}

Migration has always been a significant factor in population growth in New Zealand and immigration policies have traditionally favoured migrants of British race and culture; recently however, restrictions on other migrants have been lifted (Anderson, 1997, p. 73).

In the early 1970s the United Kingdom and Australia accounted for almost three-quarters of the origins and destinations of New Zealand permanent and long-term (PLT) immigrants (New Zealand Planning Council, 1991, p. 43).

The 1986 policy review removed the source country preference. As a result, New Zealand has become accessible to immigrants from a wide range of countries. In the 1986 Review of Immigration Policy, immigrants from all parts of the world were treated as a whole:

New Zealand is a country of immigration. The Maori people established themselves as the tangata whenua after historic voyages of migration from countries in the Pacific. Large scale immigration from European countries, particularly the United Kingdom, over the last 200 years, changed the ethnic balance and altered the cultural base of New Zealand. This in turn has been modified by more recent migration movements from the South Pacific and countries from the Pacific rim. Immigration has molded our national characteristics as a Pacific country and given our community richness and cultural diversity. (Burke, 1986, p. 8)

As a result of this review, a wave of Asian immigration started in 1986, dominated by Chinese and Indians. In 1991 there were some 45,000 Chinese and around 30,000 Indians immigrants/settlers (McKinnon, 1996, p. 51). Since then, more Chinese from the People's Republic of China have moved to New Zealand. According to Immigration New Zealand statistics, in May 2011, Chinese were the second largest migrant group with more than 94,000 residents, after Great Britain with more than 121,000 (Immigration New Zealand, 2011, table R1).

The 2006 Population Census of New Zealand also shows that in Hamilton, Chinese were the largest ethnic groups of newcomers (less than 3 years) (21\%) and the second largest (15\%) longer term migrants (3 years or longer)(Reijgersberg, 2009).

Although the number of Chinese migrants has been high, it does not mean that all of them will stay. Liangni Liu, a doctoral student at Auckland University found that many Chinese migrants saw coming to New Zealand as a stepping stone. She said "Gaining New Zealand residency or citizenship will give them a legal status to 
move to a more prosperous country, like Australia". Immigration New Zealand says 14,868 Chinese approved for residence between 2001 and 2008 are not now in New Zealand (Tan, 2010).

It appears that New Zealand has no problem attracting immigrants but has difficulty in retaining them. From the migrant support point of view, it looks like much has already been done. For example, English Language Partners NZ Inc. (formerly National Association of ESOL Home Tutor Schemes Inc.), formed in 2009, delivers English language tuition and settlement support to adult refugees and migrants. They have 23 branches in New Zealand and a range of services including a Home Tutor Scheme which is a voluntary community-based English language service available to any new settlers who need to learn English but are unable to attend classes. The service is mainly teaches practical day-to-day 'living English' language skills. Tutors and learners meet regularly (generally 1 hour weekly), usually on a one to one basis, for approximately one year. English Language Partners NZ is funded by the Tertiary Education Commission and a number of community funding bodies including Lottery Grants, but the service is not able to fully meet the demand. J. Field (personal communication, June 21, 2011), Manager of English Language Partners Waikato commented, "we have about 500 learners on our data base and 200 tutors but there are still about 100 on the waiting list. As well as the waiting list, many of the learners would like to meet the tutor twice instead of just once a week."

Apart from language assistance, in 2001 the Minister of Senior Citizens launched the New Zealand Positive Ageing Strategy. One of the goals of the Strategy was to provide "a range of culturally appropriate services that allow choices for older people" (Dalziel, 2001, p. 21), hoping to provide better assistance for older immigrants.

In Hamilton, the Waikato Migrants Resource Centre provides a number of programmes including settlement support, an interpreting service, newsletters, resource manuals and various social and sport events in order to support refugees and new migrants (Waikato Migrant Resource Centre, n.d.).

Since 2005, Hamilton City Council has hosted an annual Ethnic Community Listening Forum to address issues in social and cultural connectedness, health and wellbeing, education, language \& literacy and employment \& financial independence (Yeung, 2011). This forum identified that the availability of information and the accessibility of information, including multi-lingual signage, were major problems for Chinese migrants. Many older Chinese came to New Zealand under the Family Reunion category and would be too old to pick up a new language (English) easily and they tend not to ask for help when needed. Instead they rely on family members; therefore they feel isolated and depressed. A second issue was that Chinese immigrants with small businesses had difficulty with advertising and promotion.

As discussed over the years, many programmes in various aspects have been provided for immigrants, the question is whether these programmes are effective and sufficient and if they address the key issues at all, or whether something more should be put in place.

\section{PURPOSE OF THE STUDY}

This study was intended to better understand recent (post 1990s) Chinese migrants' reasons for coming to New Zealand, their feelings and experiences while they are living here and their future intention for residency.

The specific objectives are to ascertain:

a) the main reasons for Chinese migrants coming to New Zealand

b) the things that make Chinese migrants feel good about and enjoy

c) the things that Chinese migrants feel are unpleasant and do not enjoy

d) their future intention to either stay in New Zealand, go back to China or to move to another Western country and the reasons for their choices

The findings will be a useful reference for potential Chinese immigrants, and may alert them to matters that they need to consider beforehand. 
Central government, local government, education institutes and community service agencies may also find this research informative for future planning and policy formulation.

\section{METHODOLOGY}

Responses were sought from sixty New Zealand residents or citizens who had arrived from the People's Republic of China since the 1990s. All respondents were based in Hamilton, the fourth largest city in New Zealand with a population of 143,000 (Hamilton City Council, 2011) of which more than 26,000 were migrants and nearly 4,000 were from the P R China (Reijgersberg, 2009).

A sample size of sixty was deemed to be appropriate due to the exploratory nature of the research and the use of qualitative method (Malhotra, 2009, p. 374). The actual project time did not allow a larger sample.

The research design approved by the Wintec Human Ethics in Research Committee, confirming appropriate confidentiality and anonymity practices were maintained.

Since the survey questions potentially invited respondents to reveal some personal or even sensitive information, it was neither practical nor ethical for the researcher to use random or convenience sampling methods. In order to have unbiased and workable samples, a snow ball sampling method was adopted (Malhotra, 2009, p. 379). An initial five respondents were suggested by a local (Hamilton) Chinese newspaper editor, these five persons also knew the researcher so they were willing to come for face-to-face interviews. After the interview, each was asked to provide further referrals if they were happy with the experience.

The following four open-ended questions were used allowing respondents to express their attitudes or opinions without the bias associated with restricted responses to predefined alternatives (Malhotra, 2009, p. 338).

1. What are the reasons that you moved to New Zealand?

2. What are the things that you enjoy most while you are living in New Zealand?

3. What are the things that you do not enjoy while you are living in New Zealand?

4. What is your intention for the future? Stay in NZ? Move back to China? Move to another country? Why?

All interviews were conducted in Putonghua (Mandarin) supported with English and were audio recorded for transcription purpose. The length of interviews varied between twenty five to sixty minutes depending on how much individual respondent wanted to contribute on top of the four questions.

To make they feel comfortable, respondents were invited to choose the place of interview Twenty respondents chose to carry out the interview at their home, feeling relaxed and comfortable (Malhotra, 2009, p. 218); 23 decided to do the interview at the interviewer's office; 15 respondents had the interviews at their office and two did the interviews at the researcher's home.

Respondents' replies were categorised and coded for analysis purpose and Microsoft Excel was used to analyse the data; the function 'Pivot Table' was found to be particularly useful to pinpoint various co-relations, tables and charts.

\section{FINDINGS}

\subsection{Background Of Respondents}

Of the 60 respondents, 34 were males and 26 were females; 43 of them were between the age of 20 and 50 , six were over 60 , and two were in their late teens.

In terms of occupations, more than half (35) of the respondents were professionals, ten were retirees but only four of the retirees were over the age of sixty. Eight were students and seven fell into the 'others' category. The others include business owners, part-time workers and people seeking employment. 
Most of the respondents (40) had been in New Zealand between five to ten years, twelve of them for more than ten years and eight for less than five years.

\subsection{Main Reasons Chinese Immigrants Come To New Zealand}

More than half (32) of the respondents first came to New Zealand to study, then chose to stay and work here. The other major reasons were older Chinese (16) either following their sons or daughters under family reunion schemes or (9) hoping to provide a better educational environment for their young children. Two respondents simply wanted to have a change and one wanted to know more about the world outside China.

\subsection{Positive Feelings/Good Experience In New Zealand}

For the majority of the respondents (50 out of 60) across all age groups and occupations, the aspect of New Zealand they most enjoyed was the clean, green, natural environment and good weather.

The second most common factor, reported by 32 Chinese migrants was the lower work stress and the slower pace of New Zealand. This was particularly important to working people (aged between 20 and 60).

More than half of the respondents (32) found local Kiwis were nice and friendly and reported that there were fewer interpersonal conflicts in New Zealand.

Parents (11) with young children and older Chinese immigrants liked the welfare system and the teaching methods used here.

Younger respondents ( $<$ age of 50) found that New Zealand was a fair society providing equal opportunity for everyone.

Older respondents believed that New Zealand had a good political system.

\section{$5.4 \quad$ Negative Feelings/Experience In New Zealand}

Racism was the top negative experience that Chinese migrants felt, with the exception of the two young students, 31 of the respondents across all age groups had experienced some degree of racism and / or negative media reports towards Asian immigrants.

Thirteen respondents under the age of 50 felt that New Zealand was boring and lacked entertainment.

Eleven respondents (between age 20 and 50) said it was hard to fit in the New Zealand society.

Older and a few of the young Chinese migrants encountered language problems.

Nine respondents across most age groups had experienced teenage drunkenness and theft problems.

Nine respondents supporting families said that living costs were getting more expensive.

Some younger respondents $(20-30)$ and older people (50+) with young children felt that New Zealand is too small and did not provide enough opportunities for their next generation.

\subsection{Future Intention}

Overall, half (31) of the respondents reported that they would stay in New Zealand because they had settled well and felt generally happy here. Of those over the age of 50, all but one (14 out of 15) would stay. 
Eight Chinese migrants between the age of 20 and 50 would go back to China for better career opportunities. Another 10 respondents under forty would move to other western countries (USA, UK, Australia) either for better higher education or career options. A few of these reported that they might come back for better early childhood or primary education for their young children.

The rest of the respondents (11) still had to decide upon their future intention depending on their partner's or children's plan, or their parents' health conditions (those still in China).

In terms of occupation, only 15 of the 35 professionals said they would stay in New Zealand. The other 20 stated they would either go back to China, to another western country, or were undecided yet. Most retirees and 'others' chose to stay. Of the eight students, the two teenagers planned to study in other western countries, two would stay, and the other four were undecided.

For more recent (less than 5 years) Chinese migrants, most decided to stay because of the reasons mentioned in 5.3. The same applies to those who had been living in New Zealand longer than 10 years, because they were used to the life style and did not want to experience the upheaval of further changes.

The 40 respondents who had been in New Zealand for 5 to 9 years sent interesting signals. Just over $40 \%$ of the respondents would stay in New Zealand. Close to a quarter intended to move to other western countries for either better job opportunities or higher education. A further $20 \%$ were unsure whether to stay or not. Of these 'undecided', more than a quarter had been in New Zealand between 5 and 9 years.

Of the 31 Chinese immigrants who experienced racism and negative media comments towards immigrants, 17 said they would stay, five would go back to China, only two would move to other western countries, and seven were unsure at this stage.

For the thirteen respondents who felt bored in New Zealand, only three would stay in New Zealand and five would either go back to China or move to other western countries. Five still had to decide their future.

Of the eleven respondents who expressed that it was 'hard to fit in', five would stay, four would go back to China, and only one would move to another western country, while one was undecided yet.

For the eleven respondents saying that limited English leads to 'lots of problems', eight would stay in New Zealand, two would go back to China, and one had not decided, none considered moving to other western countries.

\subsection{Main Reasons Chinese Migrants Chose To Stay In New Zealand}

The most frequent reason that respondents (31) gave for choosing to stay in New Zealand was 'Clean \& green natural environment/Good weather' (77.4\%) followed by 'Nice and friendly people' (61.3\%) then 'Less work stress/slower pace' (48.4\%). 'Good social welfare' (29\%) and 'Good education for children' (16.1\%) were also contributing factors.

\subsection{Main Reasons Chinese Migrants Chose To Go Back To China}

Of the eight respondents who chose to go back to China, 'Racism and negative media comments towards Asians' were the main factor $(62.5 \%)$, followed by 'Hard to fit in' (50\%) and 'Bored' $(25 \%)$ and 'English based problems' $(25 \%)$.

\subsection{Main Reasons Chinese Migrants Chose To Move To Other Western Countries}

'Boring, not much happening' was the leading reason (30\%) for the 10 respondents who intended to move to another western country. Four further reasons of equal importance were 'Racism', 'Expensive living costs / high taxation', 'Problem teenagers' and 'People are less friendly now'. 


\subsection{Further Comments From Respondents}

At the end of each interview, respondents were probed for further information. It was suggested that when moving to a new country like New Zealand, Chinese immigrants should do it when they were young for easier adaptation, learn English well if they want to stay in New Zealand and get a better job, be proactive and communicate with locals such as through playing sports. Some recommended that the New Zealand Government should assist Chinese entrepreneurs to start their small businesses and provide local business networks. One respondent suggested that New Zealand needed more immigrants (finance and manpower) to explore the potential of the South Island in agriculture such as in the wine industry (see appendix 1).

\section{LIMITATIONS}

As noted in Section 4, given the budget and time constraints this study was carried out only in Hamilton, and although a sample size of 60 was deemed to be enough to provide reasonable indications, it is not large enough to draw definite conclusions.

Further studies with larger sample size in greater cities like Auckland, Christchurch and Wellington may furnish a more complete picture.

\section{CONCLUSIONS AND RECOMMENDATIONS}

In summary more than half of the respondents first came to New Zealand for tertiary education and then stayed for the good environment, relaxed pace of life and nice people. Some other migrants came under the family re-union category.

There was no major difference found between male and female respondents regarding the things that they enjoyed most and the negative aspects of living in New Zealand, however the males paid more attention to politics.

The results show that the longer Chinese immigrants live in New Zealand, the less willing they are to move, especially back to China.

Those who had English problems and found it hard to fit in to New Zealand were more likely to go back to China instead of moving to another western country.

Chinese migrants enjoyed New Zealand's clean, green natural environment, less stressful life style, kind and friendly interpersonal relationships, good welfare system for children and old people and living in a fair society.

Most migrants had experienced a minor degree of racism, felt it was hard to fit in the society due mainly to language problems, encountered some teenage problems, and had limited career and business opportunities in New Zealand.

Retirees and females felt more pressure relating to living costs because they dealt with grocery shopping.

New Zealand has been able to attract both young and old Chinese immigrants for reasons like education, its good environment, and generous social welfare. Nevertheless, these factors alone cannot guarantee that educated and trained Chinese migrants will stay and contribute to the country.

Chinese immigrants believed New Zealand provides good education in the early childhood and secondary education sectors but tertiary education is behind countries like USA, UK and Australia. As indicated by the 2010 QS World University Rankings, all the (New Zealand) universities have slid over the year, except Wellington's Victoria University (Field, 2010, para. 4). New Zealand Government and Tertiary Education Commission have to address this serious issue. 
Most Chinese immigrants who experienced racism and negative media comments towards Asians believed they were just minor issues and did not represent mainstream Kiwi opinions and attitudes. They also believed that other western countries would have similar racist situations, and there was no point to move for this particular reason. Professionals came upon more racism and drunk teenagers because they had more chances to go out after work and during weekends. A small number of Kiwis, particularly the young ones, might be too conservative or ignorant to accept different cultures, which may put off Asian immigrants. Multicultural education is needed from junior schools to improve the situation otherwise the image of being a nice and friendly nation may be at risk.

Skilled migration flows into New Zealand are important to the Department of Labour's goal of building New Zealand's workforce and attracting (and retaining) talent to contribute to the nation's economic transformation (Badkar, Callister, Krishnan, Didham, \& Bedford, 2007). But the results of this study show that New Zealand is losing young Chinese professional migrants and keeping mostly the older ones. Suitable policies should be developed to retain the young Chinese work force; otherwise the country may forfeit social benefits to the young and old migrants, but get limited productivity from Chinese immigrants overall.

A number of respondents expressed the concern that the business and career future in New Zealand is limited. Some Chinese immigrants found a good job in New Zealand; however many came to New Zealand and retired early (before 60) because of language and business networking problems. Some immigrants over the age of 30 still studied various levels of English courses.

Compared to other big cities in the world, New Zealand is relatively quiet in many Chinese migrants' eyes, particular for the younger respondents. Although both the central and local governments have been trying to provide more facilities and events, with the size of the existing population, it may not be easy to improve the situation in the short run. As mentioned by John Key, Prime Minister of New Zealand "... having an international convention centre for Auckland, if you want Auckland to compete with Sydney and Melbourne and the likes, it is really important. It will make Auckland a much more interesting place, support a lot more business and jobs, I think it's a good thing" (Key defends govt support, 2011).

New Zealand has signed Free Trade Agreements with China, Korea and most likely with India (Trevett, 2011, para. 1) which should help develop the economy, creating more jobs and investment in the long run. A study carried out by Professor Colleen Ward of Victoria University concludes that immigrant groups, Maori, and New Zealand European groups, felt the best way immigrants could behave in their new country was to integrate, but language difficulty was a big challenge (Groser, 2002). Therefore in the short term, workshops, re-training programmes as well as information about western / Kiwi cultures should be provided further.

It is important we hold on to New Zealanders who have been educated and trained here.

To keep young productive migrants, New Zealand has to provide more facilities, better events and activities, lower tax rates and reduce teenage offences.

New Zealand also has to maintain the clean, green image as well as being a kind and helpful society. Equal employment opportunity would enhance the Chinese working population to stay.

McCarten (2011, para. 20) states "If we can't even offer our own children decent opportunities, I can't see how we can offer new immigrants enough to stop them moving to Australia either."

It is recommended that a similar study with a larger sample size in other major cities be undertaken to confirm the above findings.

\section{8. 'FURTHER COMMENTS' FROM RESPONDENTS}

- "Chinese students need to learn English well if they want to have a better job and stay in NZ"

- "Immigration - should do it early and young"

- "I want to learn how to interact with locals" 


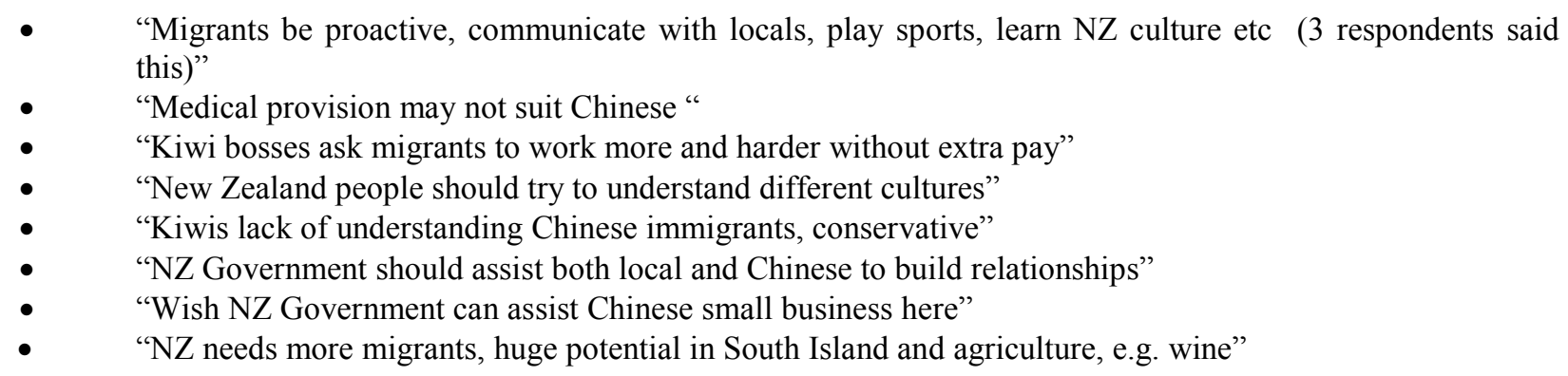

\section{AUTHOR INFORMATION}

Deniss Yeung is a Principal Lecturer in the School of Business, Waikato Institute of Technology, New Zealand. He is a Chartered Marketer (U.K.) with strong research interests in international students, Chinese migrants and not for profit organisations and issues. He has had papers published in a number of international journals and has presented in conferences in New Zealand, Australia, China, Thailand and Singapore. E-mail: Deniss.yeung@wintec.ac.nz

\section{REFERENCES}

1. Anderson, L. (1997). People on the move: Migration - a cultural process. New Zealand, Longman.

2. Badkar, J., Callister, P., Krishnan, V., Didham, R., \& Bedford, R. (2007). Gender, mobility and migration into New Zealand: A case study of Asian migration. Social Policy Journal, 32: 152-180.

3. Betz, C. L. (2008). Immigrant children: Unmet needs and a myriad of nursing concerns. Journal of Pediatric Nursing, 23(3), 157-160.

4. Burke, K., (1986, August). Minister of Immigration, Review of immigration policy. AJHR, G.42, p. 8.

5. Collins, S. (2005, March 12). Quarter of NZ's brightest are gone. New Zealand Herald. Retrieved from http://www.nzherald.co.nz

6. Dalziel, L. (2001). The New Zealand Positive Ageing Strategy. Wellington: Senior Citizens Unit, Ministry of Social Policy.

7. Field, M. (2010, September 9). Kiwi universities slip in world rankings. New Zealand Herald. Retrieved from http://nzherald.co.nz

8. $\quad$ Grass looks greener in Oz. (2011, June 23). Waikato Times, p. 6.

9. $\quad$ Groser (2002)

10. Hamilton City Council. (2011). About Hamilton. http://hamilton.co.nz/page/pageid/2145832768

11. Ho, E. S., Au, S., Bedford, C., \& Cooper, J. L. (2003). Mental health issues for Asians in New Zealand - A literature review. Wellington, New Zealand: N.Z. Mental Health Commission.

12. Ho, E., Cooper, J. \& Ip, Q. (2007). Safety awareness and service utilisation among older Asians. Wellington, New Zealand: Accident Compensation Commission.

13. Immigration New Zealand. (2011, May 2). People included on residence applications decided, by nationality and financial year of decision, Table R1. Retrieved from http://www.immigration.govt.nz/migrant/general/generalinformation/statistics/.

14. Ip, M. (2006). Chinese. In J. Phillips (Ed.), Settler and migrant peoples of New Zealand. Auckland, New Zealand: David Bateman.

15. Key defends govt support for Sky City deal. (2011). Retrieved from http://www.nzherald.co.nz/business/news/article.cfm?c_id=3\&objectid=10731924

16. Malhotra, N.K. (2009). Basic marketing research: A decision-making approach. Pearson.

17. McCarten, M, (2011, June 26). We've failed our kids and they're off to Oz. New Zealand Herald. Retrieved from http://www.nzherald.co.nz

18. McKinnon, M. (1996). Immigrants and citizens: New Zealanders and Asian immigration in historical context. Wellington, New Zealand: Institute of Policy Studies, Victoria University of Wellington.

19. New Zealand Planning Council. (1991). On the move: Migration and population - trends and policies. Population monitoring group, report No. 6, Wellington, New Zealand: Author. 
20. Reijgersberg, L. (2009). Newcomer communities: Hamilton \& Waikato District, Community Profile Report.

21. Tan, L. (2010, May 4). Chinese flocking to NZ but it's only a stopover - study. New Zealand Herald. Retrieved from http://nzherald.co.nz/news/print.cfm?objectid=10642547

22. Trevett, C. (2011, June 29). Free trade support from Indian PM. New Zealand Herald. Retrieved from http://www.nzherald.co.nz

23. University of Waikato. (2007). Safety awareness and service untilisation among older Asians. New Zealand: Elise Ho, Jenine Cooper and Queenie Ip.

24. Waikato Migrant Resource Centre. (n.d.). Retrieved from http://www.wmrc.org.nz/page/wmrc_125.php.

25. Yeung, P. (2011). $7^{\text {th }}$ Ethnic Communities Listening Forum, 2011. Report. Hamilton City Council. Retrieved from http://hamilton.co.nz/page/pageid/2145827047/Ethnic_Communities 